\title{
ESTUDO COMPARATIVO ENTRE ROSCAS USINADAS E CONFORMADAS NO AÇO SAE 1045 E NO ALUMINIO AA 7075-T6 COM A VARIAÇÃO NO NÚMERO DE FILETES
}

\author{
Pedro Márcio do Carmo Silva ${ }^{(1)}$ (pdromarcio@gmail.com), Guilherme Lopes Brandão(1) \\ (gui.lopes.brandao@gmail.com), Camilo Lellis dos Santos ${ }^{(1)}$ (camilo_santos@ufsj.edu.br), Artur Mariano de \\ Sousa Malafaia (1) (arturmalafaia@ufsj.edu.br) Lincoln Cardoso Brandão ${ }^{(1)}$ (lincoln@ufsj.edu.br) \\ (1) Universidade Federal de São João del- Rei (UFSJ) - Departamento de Engenharia Mecânica - DEMEC - Praça Frei Orlando,170 - \\ Centro
}

RESUMO: Roscas são elementos de fixação de grande importância na montagem de componentes mecânicos. A indústria mecânica utiliza diversos tipos de perfis de rosca e diâmetros padronizados na montagem de máquinas e equipamentos. Dentre os diâmetros padronizados de rosca métrica, M6, M8 e M10 são os principais, sendo o diâmetro M8 o mais usado. Portanto, o objetivo desse trabalho foi medir e comparar a carga máxima de tração suportada por roscas internas M8 no aço SAE 1045 e no alumínio AA 7075-T6, com 1,3 e 5 filetes de rosca, fabricadas pelo pelos processos de usinagem e conformação. Foram utilizados parafusos de grau 12.9 para o auxílio no tracionamento das roscas com velocidade de deslocamento de $1 \mathrm{~mm} / \mathrm{min}$ e corpos de prova com diâmetro externo de $31 \mathrm{~mm}$. Após os ensaios e feitas as análises necessárias, pode-se observar que as roscas conformadas apresentaram maior resistência nos dois materiais. Por outro lado, as roscas no aço SAE 1045, fabricadas por conformação apresentaram as maiores resistências nos testes de tração. Além disso, pode-se concluir que o parafuso utilizado não foi capaz de suportar as tensões aplicadas na rosca de aço SAE 1045 conformada com 5 filetes.

PALAVRAS-CHAVE: Roscas Usinadas, Roscas conformadas, roscas internas M8, Teste de tração.

\section{COMPARATIVE STUDY BETWEEN MACHINING AND FORMING THREADS IN SAE 1045 STEEL AND AA 7075-T6 ALUMINIUM WITH VARIATION IN NUMBER OF FILETS}

ABSTRACT: Threads are very important fasteners in the assembly of mechanical components. The mechanical industries use several types of threaded profiles and standard diameters in the assembly of machines and equipment. Among the standard metric thread diameters, M6, M8, and M10 are the main ones, with diameter M8 being the most used. Therefore, the objective of this work was to measure and compare the maximum tensile load supported by M8 internal threads on SAE 1045 steel and AA 7075-T6 aluminium, with 1, 3, and 5 thread fillets, manufactured by machining and forming processes. Grade 12.9 screws were used to aid in thread tensile test with speed of $1 \mathrm{~mm} / \mathrm{min}$ and workpieces with an external diameter of $31 \mathrm{~mm}$. After the tests and the necessary analyses, it can be observed that the formed threads presented higher resistance in both materials. On the other hand, threads in SAE 1045, manufactured by forming process showed the highest tensile strengths. Furthermore, it can be concluded that the screw used was not able to withstand the stresses applied to the SAE 1045 steel thread formed with 5 threads.

KEYWORDS: Machined Threads, Formed Threads, M8 internal threads, Tensile Test. 


\section{XIX \\ CONEMI}

FENEMI

Como a Engenharia Mecânica e Industrial podem melhorar o Agronegócio do Brasil Anais do XiX CONEMI - Congresso Nacional de Engenharia Mecânica e Industrial | $\mathbf{2}$ de $\mathbf{1 1}$ 


\section{XIX CINEMI}

\section{INTRODUÇÃO}

Dentre as operações de rosqueamento das indústrias metal-mecânicas, pode-se distinguir duas grandes classes de trabalho com os metais: os processos de usinagem e os processos de conformação. As operações de usinagem conferem à peça a forma, a dimensão, ou o acabamento, com a remoção de cavaco, enquanto nos processos de conformação há a constância do material que passa por alterações em sua forma mediante a deformação plástica. Esse é um processo ainda pouco usado nas empresas que fabricam componentes roscados e executam essa operação na própria máquina operatriz. A laminação de roscas tem grande vantagem sobre processos similares devido ao fato de não produzir cavacos e, por isso, não necessitar de processos de reciclagem específicos. Entretanto, manuais específicos e conceitos técnicos com informações precisas sobre esse processo ainda são grandes lacunas para sua efetiva aplicação em todos os materiais utilizados em produtos manufaturados (MACIEL,2013; CARVALHO, 2011).

Segundo Lauro et al. (2010), componentes mecânicos podem ser unidos por meio de fixação permanente, soldagem ou fixação removível, com a utilização de parafusos, rebites, pinos, dentre outros. Por causa da facilidade na substituição e reparo, o uso de parafusos se torna mais comum, havendo poucos equipamentos que não usam parafusos para fixação. Considerando o período do início da revolução industrial até a década de 1980, pode-se dizer que a evolução do processo de roscamento dentro da indústria foi modesta. Basicamente, o processo mais usado de roscamento interno sempre foi realizado na indústria com ferramentas denominadas machos. Este processo promove, assim como nos processos de torneamento, fresamento e furação, a geração de cavacos que são na sua maioria expulsos pelos fluidos de corte durante a usinagem. (CARVALHO, 2011)

No processo de rosqueamento interno, cada dente do macho laminador da redução de guia funciona como uma ferramenta trabalhando individualmente assim que entra em contato com a parede do furo a ser roscado. Entretanto, no rosqueamento por conformação o macho laminador gera a deformação do material que ocorre à frente dos dentes da ferramenta. Assim, o material deformado vai sendo acumulado entre as faces dos dentes, do lado das estrias do macho laminador. É esse material que vai formando o perfil da rosca à medida que os outros dentes vão deformando mais o material e acumulando-o entre as faces dos dentes, até que o último dente da redução de guia do macho trabalhe o material e este assume a forma da crista final do filete (CARVALHO, 2011).

Segundo Stemmer (1995), a resistência ao cisalhamento dos filetes de rosca aumenta devido a deformação dos grãos do material acompanhar o contorno dos filetes. A ruptura por cisalhamento (fratura do material quando submetido a um esforço mecânico) ocorre geralmente de forma intergranular ou transgranular. Com o alongamento dos grãos devido ao processo de conformação, fica mais complexo de ocorrer fratura transgranular que passa pelo grão devido ao sentido de aplicação dos esforços e também de ocorrer a intergranular que contorna os grãos, pois esses contornos estarão perpendiculares a aplicação dos esforços (OLIVEIRA, 2016). 


\section{$\mathrm{XIX}$ \\ CENEMI}

Se tratando de métodos que envolvem a remoção de cavacos, os mais utilizados, visto que no sistema de montagem de peças o rosqueamento é mais indicado devido à sua versatilidade. Assim, o rosqueamento por usinagem se sobrepõe ao processo realizado por conformação, uma vez que o primeiro é muito mais difundido. Pode-se dizer que, dentre os processos de usinagem, o rosqueamento é, segundo Reis et al. (2005), um dos mais difíceis de ser executado devido à complicada remoção de cavacos e lubrificação na zona de corte, além da necessidade de uma relação inalterável entre a velocidade de corte e o avanço, definida pelo passo da ferramenta. (CARVALHO, 2011)

O processo de geração de roscas internas com machos ocorre, onde o perfil é construído com o deslocamento da ferramenta no sentido axial e com um movimento rotativo simultâneo. O macho apresenta um formato cônico na sua parte inicial o que permite que as arestas de corte executem a operação removendo seç̧ões de corte pequenas no começo e estas aumentem de forma progressiva. Além disso, na construção da ferramenta existem arestas de corte radiais que dividem as secções de corte no sentido radial e axial, permitindo a geração do perfil da rosca de forma gradual (Komura et al., 1990).

Assim, mais pesquisas experimentais com o objetivo de conhecer a influência das variáveis durante a laminação de roscas necessitam ser realizadas. Dessa forma, o processo de laminação de roscas poderá se tornar mais atraente, principalmente, se os tempos de produção forem idênticos ou menores que os tempos do tradicional processo de usinagem de roscas, pois a não geração de cavacos já torna o processo de laminação de roscas bastante competitivo para o setor produtivo. (OLIVEIRA, 2016)

O aço SAE 1045 é amplamente utilizado na indústria, devido a sua vasta aplicabilidade. Possui boa relação entre resistência mecânica e resistência a fratura, tendo como principal característica sua resistência a tensão e razoável tenacidade. O alumínio 7075 T6, extremamente leve, possuindo alta relação entre resistência e peso, alta resistência a corrosão e dureza, além de muitas outras características beneficiárias na indústria. Todavia, possui preço elevado em relação aos demais alumínios e aços. Sendo assim, torna-se necessário o estudo deste tipo de material através do rosqueamento, comparando os resultados obtidos com aço em SAE 1045, relacionando o comportamento de cada material quando submetido a tração e quando se varia o número de filetes.

\section{METODOLOGIA}

Para a realização do estudo, foram utilizados corpos de prova de aço SAE 1045 e alumínio AA 7075T6 com $31 \mathrm{~mm}$ de diâmetro externo $15 \mathrm{~mm}$ de altura, possuindo roscas usinadas e conformadas. Para a preparação das amostras foi utilizado um centro de usinagem CNC com 10.000 rpm de rotação no cabeçote e $12,5 \mathrm{~kW}$ de potência no motor principal, onde ocorreu a furação e rosqueamento das 


\section{$\mathbf{X I X}$ \\ CENEMI}

mesmas com machos de roscar modelo $\mathrm{M} 8-\mathrm{ISO} 2 / 6 \mathrm{H}$, e conformado modelo M8-6HX ambos com cobertura de titânio e da marca Emuge-Franken, conforme a Figura (1).

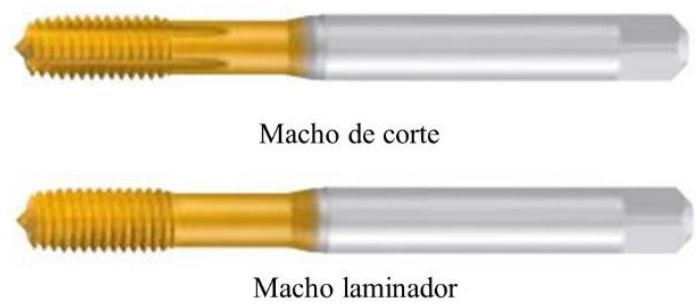

Figura 1. Machos de roscar utilizados nos experimentos (Fonte: Autoria própria)

Para tal preparação dos corpos de prova, foi utilizado um dispositivo que possibilitou a fixação dos corpos de prova cilíndricos na mesa do centro de usinagem, com pode ser visto na Figura (2). Foram fabricados 9 corpos de prova de alumínio AA 7075-T6, sendo 3 corpos de prova com um filete, 3 corpos de prova com três filetes e 3 corpos de prova com cinco filetes, possibilitando assim que cada experimentos de tração fosse repetido três vezes. Seguindo a mesma metodologia foram fabricados também 9 corpos de prova de aço SAE 1045, sendo 3 corpos de prova com um filete, 3 corpos de prova com três filetes e 3 corpos de prova com cinco filetes. Assim, no total foram fabricados e testados 18 corpos de prova.

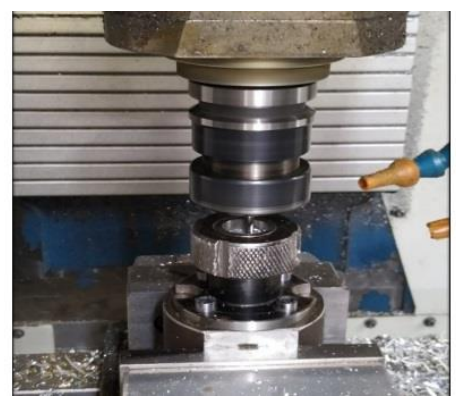

FIGURA 2. Rosqueamento dos corpos de prova (Fonte: Autoria Própria)

Após a preparação, os corpos de prova foram levados a máquina universal de tração EMIC 23-100 com capacidade de carga de 10.000 (kgf) e a velocidade de deslocamento foi utilizada foi $1 \mathrm{~mm} / \mathrm{min}$. Para que fosse possível o tracionamento das roscas através dos parafusos, foi necessário a confecção de um suporte que facilitasse a retirada dos mesmos, presos aos corpos de prova rompidos da máquina para cada etapa de experimentos. Esse suporte foi feito de aço 1045, usinado no laboratório de usinagem da instituição, em seguida, passou por uma têmpera em óleo, como observado na Figura (3). 


\section{$\mathbf{X I X}$ \\ CENEMI}

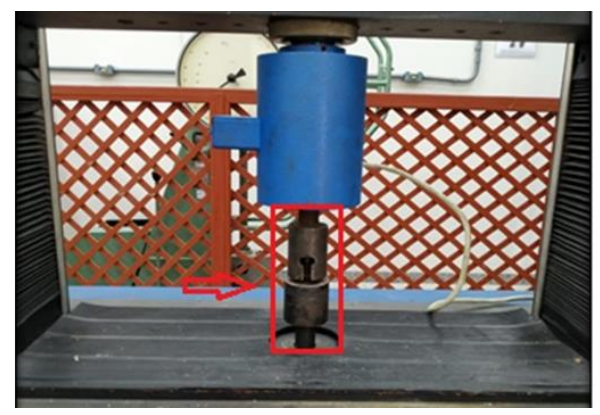

FIGURA 3. Conjunto Suporte-gabarito-amostra durante o ensaio de tração (Fonte: Autoria Própria)

Para a aquisição de dados, foi utilizado o software Stress Machine VIEW 1.0, que gerou os gráficos cedidos pela máquina por meio de conversão de sinais pelo módulo da marca National Instruments modelo NI USB-6210. Assim, foi possível encontrar a curva de tensão x deformação de engenharia juntamente com os dados de carga e tensão de escoamento, máxima e ruptura. Neste trabalho não foram considerados os mecanismos de falha das roscas, pois para isto seria necessário o corte transversal das amostras tracionadas e, como todas as amostras de um e três filetes foram destruídas, não foi possível avaliar a microestrutura das roscas.

\section{ANÁLISE DOS RESULTADOS}

Através do ensaio de tração, foram obtidos os dados necessários para as análises de resistência das roscas. Dessa forma, foi considerada apenas carga máxima de resistência das amostras, visto que é o parâmetro de referência do estudo. Para melhor entendimento através da comparação das amostras ensaiadas, gráficos foram gerados com o auxílio do software. A seguir são apresentados gráficos com três filetes de rosca para os dois materiais, pois os demais gráficos apresentaram comportamento similar diferenciando apenas nos valores de resistência. Assim, analisando-se a Figura (4), pode-se perceber que a carga máxima aplicada na amostra usinada foi maior, obedecendo aos demais ensaios realizados no Alumínio AA 7075-T6, onde não só apenas a carga máxima suportada como a tensão de ruptura foi maior.

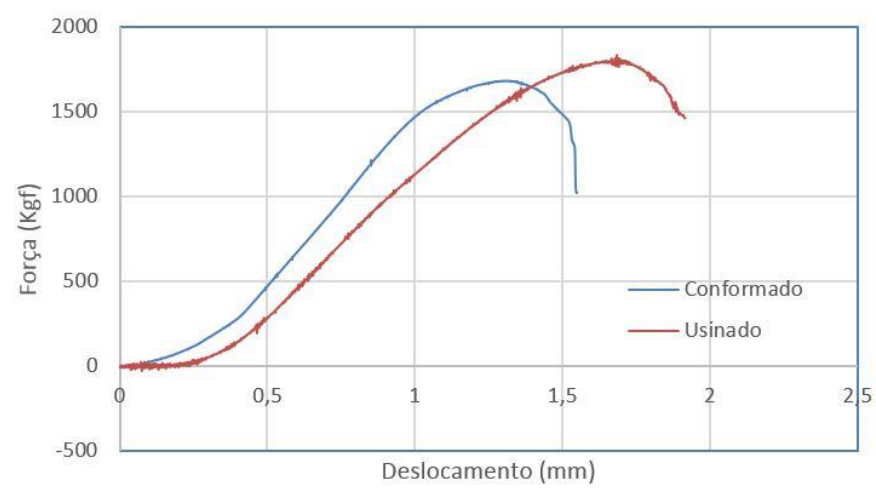

FIGURA 4. Gráfico de força-deformação da amostra de alumínio AA 7075-T6 com 3 filetes de rosca usinada e conformada (Fonte: autoria própria) 


\section{$\mathbf{X I X}$ CENEMI}

Na Figura (5) podemos observar que no aço SAE 1045, a amostra conformada obteve maior resistência a tração, tendo um comportamento inverso ao do alumínio analisado. Porém, obedecendo aos demais dados coletados com valores de resistência próximos com a variação do tipo de rosca.

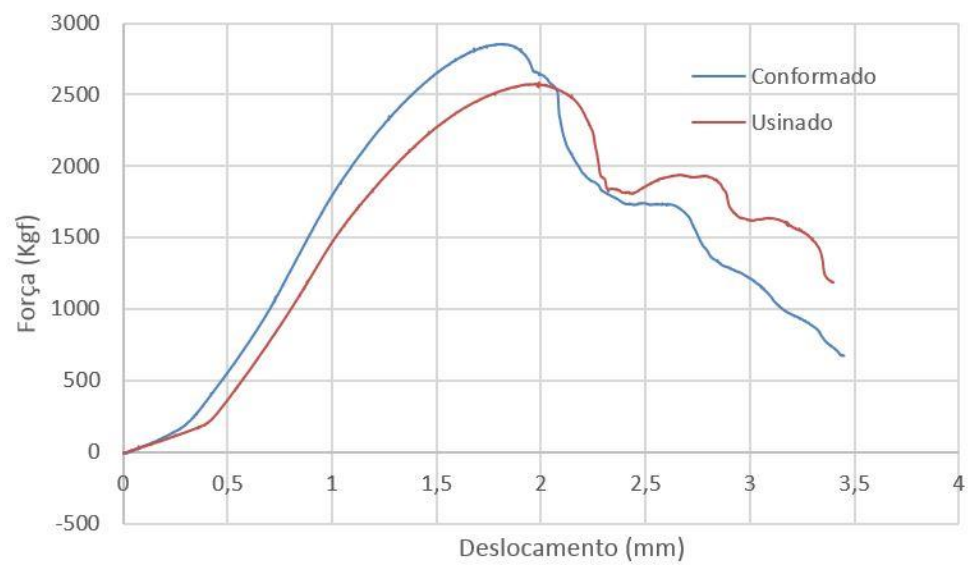

FIGURA 5. Gráfico de força-deformação da amostra de aço SAE 1045 com 3 filetes de rosca usinada e conformada (Fonte: autoria própria)

Na Tabela (1) são apresentados os resultados da análise de variância da força máxima (kgf) onde pode-se observar que apenas o número de filetes e o material tiveram influência na força máxima considerando os efeitos principais. Por outro lado, a interação entre dois fatores Filetes vs. Material e Filetes vs. Processo apresentaram influência na resposta de força máxima.

\begin{tabular}{|l|c|c|}
\hline \multicolumn{1}{|c|}{ Fonte } & F-valor & P-valor \\
\hline Filetes & 83,25 & 0,000 \\
\hline Processo & 1,35 & 0,257 \\
\hline Material & 8,39 & 0,008 \\
\hline Filetes*Processo & 4,07 & 0,030 \\
\hline Filetes*Material & 6,87 & 0,004 \\
\hline Processo*Material & 2,51 & 0,127 \\
\hline Filetes*Processo*Material & 0,18 & 0,837 \\
\hline
\end{tabular}

TABELA 1. Análise de variância para os testes de tração nos filetes (Fonte: Autoria própria)

Analisando as variações de resistência máxima do material através da Figura (6), observa-se que como era esperado a resistência do furo roscado aumenta proporcionalmente ao aumento do número de filetes rosqueados no parafuso. O valor mínimo encontrado foi de 544, $8 \mathrm{kgf}$ para um filete e o valor máximo foi de 4.647,0 kgf, para cinco filetes, que corresponde a um aumento de 752 $\%$ na resistência da rosca com um aumento de apenas 4 filetes no rosqueamento do parafuso dentro do furo.

Por outro lado, considerando o tipo de material observa-se na figura (6) (direita) que o alumínio AA 7075-T6 tem uma resistência de 36\% menor que o aço SAE 1045. Sendo o valor médio para o aço SAE 1045 de 2.848,2 kgf e o para o alumínio o valor foi de 2.092,3 kgf. Neste trabalho esperava-se que a resistência de roscas fabricadas em alumínio fosse menor que a resistência de roscas fabricadas 


\section{$\mathbf{X I X}$ \\ CENEMI}

em aço. Portanto, pode-se definir que existe uma resistência que deve ser considerada na fabricação de componentes metálicos de aço SAE 1045 e alumínio AA 7075-T6.

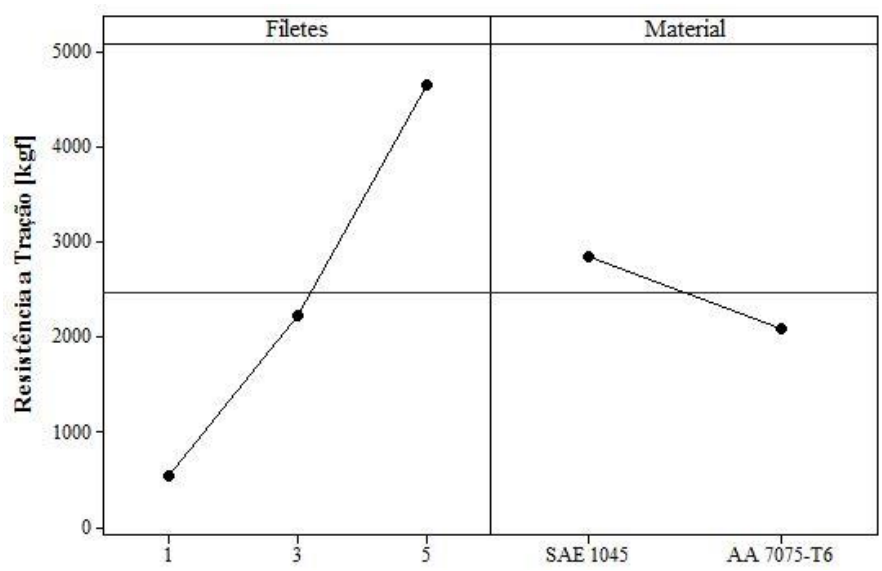

FIGURA 6. Gráfico de efeitos principais da força máxima (kgf) para amostras variando o número de filetes (esquerda) e o tipo de material (direita) (Fonte: Autoria própria)

Na Figura (7) observa-se o gráfico de interação entre número de filetes e o material. Nota-se que para 1 filete existe uma pequena tendência ao aumento de resistência considerando a variação do material, nestas condições pode-se definir que para um filete de rosca, o alumínio AA 7075-T6 tem maior resistência que o aço AE 1045, sendo esta resistência em torno de $174 \%$. Entretanto, à medida que são usados mais filetes de rosca na fixação, percebe-se não apenas que a resistência cresce, para os dois materiais, mas que o aumento da resistência é mais significativo para o aço SAE 1045 do que para o alumínio AA 7075-T6. No caso de cinco filetes de rosca nota-se uma redução de $49 \%$ na resistência das roscas mudando-se o material, do aço SAE 1045 para o alumínio AA 7075-T6. O gráfico de interação da Figura (7) confirma a tendência ao aumento da resistência das roscas proporcional ao material, o seja, roscas fabricadas em alumínio AA 7075-T6 sempre terão menor resistência que roscas fabricadas em aço SAE 1045.

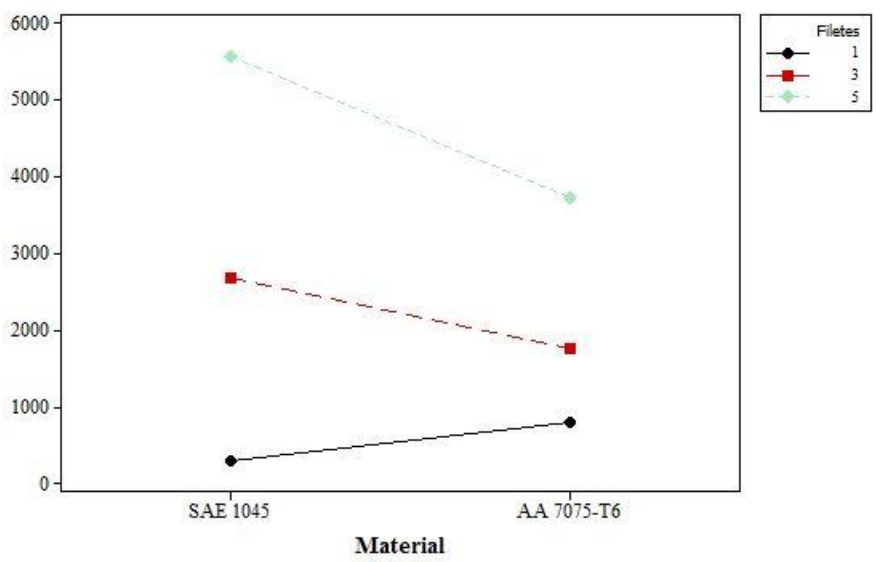

FIGURA 7. Gráfico de interação entre o número de filetes e o material (Fonte: Autoria própria) 


\section{$\mathbf{X I X}$ \\ CENEMI}

O gráfico de interação da Figura (8) mostra que ao contrário do que ocorreu com a interação do tipo de material com o número de filetes, para um filete fabricado, a resistência cai para roscas conformadas em torno de $172 \%$. Por outro lado, o aumento da resistência só pode ser percebido de forma significativa para cinco filetes, pois ocorre um aumento de $32 \%$ quando são fabricadas roscas conformadas. Para três filetes de rosca o aumento da resistência foi menor com uma variação de apenas 5\%. Neste caso deve-se considerar que o valor de 5\% está dentro do erro estatístico utilizado nestes experimentos e, neste caso, pode-se considerar que para três filetes ambos os processos apresentam a mesma resistência à tração.

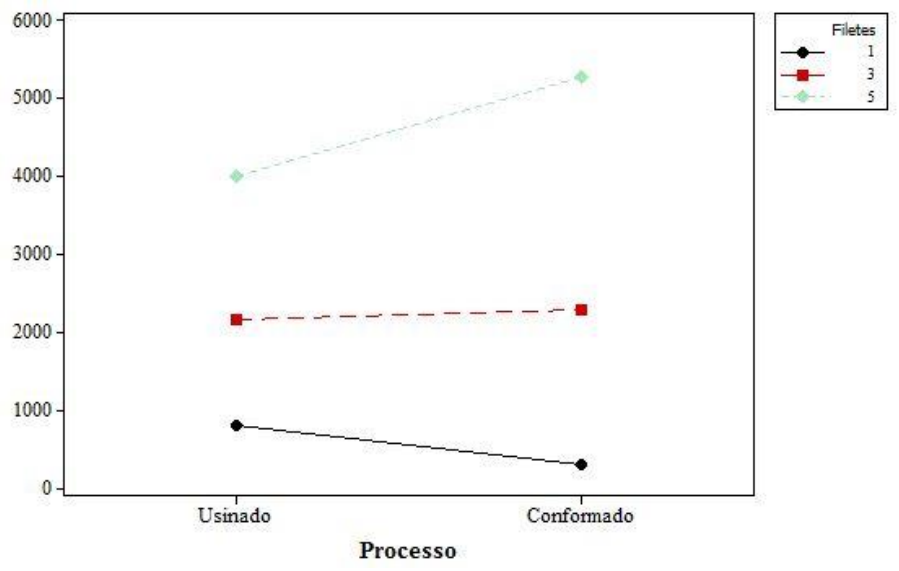

FIGURA 8. Gráfico de interação entre o número de filetes e o tipo de processo (Fonte: Autoria própria)

A força máxima suportada pelo parafuso utilizado foi menor que a força suportada pela amostra conformada de aço possuindo 5 filetes de rosca. Assim, em todos os experimentos com cinco filetes os parafusos se romperam, conforme pode ser observado na Figura (9), com uma média de valores de $4.995 \mathrm{kgf}$, sendo este valor bem acima do previsto pelo fabricante, que defini uma carga máxima de $3.550 \mathrm{kgf}$ para parafusos da classe 12.9 (Ciser, 2019). Os resultados da análise estatística com cinco filetes correspondem aos valores registrados pouco antes da ruptura do parafuso. A falha do parafuso ocorreu em uma região da parte roscada que estava fora da peça testada. Dessa forma, entende-se que a região roscada pode ter funcionado como um concentrador de tensão facilitando o rompimento do parafuso.

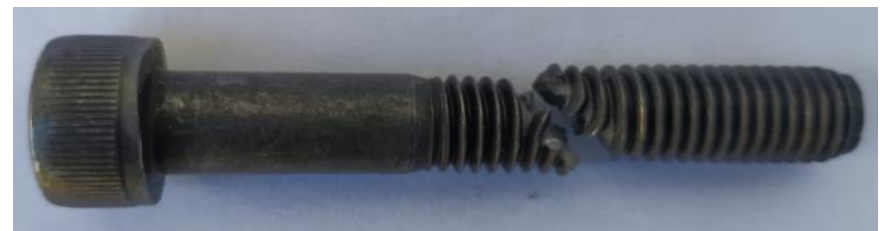

FIGURA 9. Parafuso rompido após o ensaio (Fonte: Autoria própria) 


\section{$\mathbf{X I X}$ \\ CENEMI}

\section{CONCLUSÕES.}

De acordo com os resultados obtidos no estudo das variações de resistência máxima entre o aço SAE 1045 e o Alumínio AA 7075-T6 variando o tipo de processo de fabricação e a quantidade de filetes de rosca, pode-se concluir que:

$\checkmark$ O número de filetes tem fator decisivo na montagem de produtos roscados. Considerando os materiais testados, sugere-se o rosqueamento de cinco ou mais filetes para ambos materiais nas montagens industriais;

$\checkmark$ Roscas fabricadas em peças de aço SAE 1045 terão resistência maior que roscas fabricadas em alumínio AA 7075-T6, independentemente do tipo de processo empregado na fabricação destas roscas;

$\checkmark$ Roscas conformadas tem maior resistência que roscas usinadas, porém deve-se considerar esta afirmação apenas para o rosqueamento de 5 ou mais filetes.

$\checkmark$ Considerando a resistência de tabela para o parafuso classe 12.9, a montagem com cinco ou mais filetes de rosca sempre terá uma resistência superior, devendo-se dessa forma considerar que a falha ocorrerá sempre no parafuso.

\section{DIREITOS AUTORAIS,}

Os autores são os únicos responsáveis pelo conteúdo das informações contidas neste artigo.

\section{REFERÊNCIAS}

Carvalho, A. O. Análise da dinâmica do processo de rosqueamento por conformação da liga de Magnésio AM 60. 116f. Dissertação (Mestrado)-Programa de Pós-graduação em Engenharia Mecânica, Universidade Federal de São João del-Rei, São João del-Rei, 2011.

CISER, parafusos e porcas, Informações técnicas - Uso orientativo, catálogo técnico, 16 páginas, www.ciser.com.br/download/informacoes-tecnicas, acesso em 19 de agosto de 2019.

Maciel, D. T. Estudo dos processos de rosqueamento por laminação e usinagem na liga de titânio TI-6AL-4V. Dissertação (Mestrado)-Programa de Pós-graduação em Engenharia Mecânica, Universidade Federal de São João del-Rei, São João del-Rei, 2013.

Oliveira, J. A. ESTUDO DO PROCESSO DE ROSQUEAMENTO POR CONFORMAÇÃO NA LIGA DE ALUMÍNIO 7075-T6. Dissertação (Mestrado)-Programa de Pós-graduação em Engenharia Mecânica, Universidade Federal de São João del-Rei, São João del-Rei, 2016.

Lauro, C.H., Baldo, D.; Brandão, L.C.; Christoforo, A.L.; Carvalho, A.O. Estudo da deformação de filetes de rosca interna produzidas por laminação. Anais do 1ㅇ CONEMAT - Congresso das Engenharias, Arquitetura e Agronomia. Mato Grosso, p. 686-695, 2010 


\section{$\mathbf{X I X}$ \\ CIONEMI}

Reis, A.M.; Coelho, G.A.B.; Barbosa, F.Q.; Silva, M.B. Estudo da relação entre forças axial e radial e o desgaste da ferramenta para o processo de rosqueamento interno. Anais do 30 COBEF, p. 1-101, 2005.

Reis, A.M.; Júnior, W.S.; Júnior, A.M.S.; Silva, M.B. Avaliação do desempenho de ferramentas de aço-rápido com e sem revestimento no rosqueamento interno do ferro fundido cinzento GH-190. Anais do 3o COBEF, p. 1-10, 2005.

Komura, A.; Yamamoto, M.; Ikawa, N. Study of tapping method for large size threads consideration for the oversized effective diameter by tapping. Bulletin of the Japan society of precision engineering, v. 24, № 3, p. 178-183, 1990.

Stemmer, C. E., Ferramentas de Corte 1. 1995. Florianópolis, Universidade de Santa Catarina. 